\title{
Variation in myxoid liposarcoma: Clinicopathological examination of four cases with detectable TLS-CHOP or EWS-CHOP fusion transcripts whose histopathological diagnosis was other than myxoid liposarcoma
}

\author{
KAYO SUZUKI ${ }^{1}$, YOSHITO MATSUI ${ }^{1}$, NOBUYUKI HASHIMOTO ${ }^{2}$, NORIFUMI NAKA ${ }^{2}$, \\ NOBUHITO ARAKI ${ }^{3}$, TOMOATSU KIMURA ${ }^{1}$, HIDEKI YOSHIKAWA ${ }^{2}$ and TAKAFUMI UEDA ${ }^{4}$ \\ ${ }^{1}$ Department of Orthopaedic Surgery, University of Toyama, Toyama 930-0194; \\ ${ }^{2}$ Department of Orthopaedics, Osaka University Graduate School of Medicine, Suita, Osaka 565-0871; \\ ${ }^{3}$ Department of Orthopaedic Surgery, Osaka Medical Center for Cancer and Cardiovascular Diseases, Osaka 537-8511; \\ ${ }^{4}$ Department of Orthopaedic Surgery, Osaka National Hospital, Osaka 540-0006, Japan
}

Received July 18, 2011; Accepted October 11, 2011

DOI: $10.3892 / \mathrm{ol} .2011 .480$

\begin{abstract}
Liposarcomas are separated into clinicopathological entities by a characteristic morphological spectrum and distinctive genetic changes. Myxoid liposarcoma (MLS) represents one such entity with specific chromosomal translocations leading to the generation of fusion genes, the human translocation liposarcoma (TLS)-CCAAT/enhancer binding protein $(C / E B P)$ homologous protein $(C H O P)$ or the Ewing sarcoma (EWS)-CHOP. In the present study, four cases of liposarcoma with detection of TLS-CHOP or EWS-CHOP, whose postoperative diagnosis was other than MLS (one well-differentiated liposarcoma, two de-differentiated liposarcomas and one unclassified) were examined for medical records, imaging data and histopathology. Clinical records demonstrated that three of the four cases were considerably difficult to diagnose definitively, and histopathological re-examination pointed out areas of myxomatous change as a minor component $(<10 \%)$. Their dominant components (>90\%) resembled pleomorphic sarcoma, pleomorphic malignant fibrous histiocytoma and monophasic synovial sarcoma. The current cases may represent an extreme variant of the morphological spectrum within MLS. In cases of difficulty in making definitive diagnosis of soft tissue sarcoma by standard histopathological examination and identification of myxoid stroma even as a minor compo-
\end{abstract}

Correspondence to: Dr Yoshito Matsui, Department of Orthopaedic Surgery, University of Toyama, 2630 Sugitani, Toyama 930-0194, Japan

E-mail: m-yoshito@umin.ac.jp

Key words: Ewing sarcoma-CCAAT/enhancer binding homologous protein, histopathology, myxoid liposarcoma, reverse transcription-polymerase chain reaction, human translocation liposarcoma-CCAAT/enhancer binding homologous protein, variation nent, analyzing TLS-CHOP and EWS-CHOP fusion genes may aid the diagnosis of unusual MLS.

\section{Introduction}

Liposarcomas are the most common class of soft tissue sarcoma, and are separated into distinct clinicopathological entities with a characteristic morphological spectrum and exclusive genetic changes $(1,2)$. Myxoid liposarcoma (MLS) represents one such entity with the second most common prevalence after well-differentiated liposarcoma. A significant proportion of MLS contains a cytogenetic hallmark, $t(12 ; 16)(q 13 ; p 11)$, which leads to the fusion of the CCAAT/enhancer binding protein $(C / E B P)$ homologous protein $(C H O P)$ and human translocation liposarcoma $(T L S)$ gene, generating $T L S-C H O P$ fusion transcript (3-10). In a minor population of MLS, a variant chromosomal translocation, $\mathrm{t}(12 ; 22)(\mathrm{q} 13 ; \mathrm{q} 12)$, has been documented, resulting in the Ewing sarcoma (EWS)-CHOP fusion gene (5,6,8-12). Our recent fusion gene analysis of 172 cases of adipocytic tumors, comprising 98 cases of lipoma and 74 cases of liposarcoma, established that TLS-CHOP and EWS-CHOP were specific to liposarcoma (10). However, of note, among the distinct entities of liposarcomas, the fusion genes were detectable in four cases whose histopathological diagnosis was other than MLS. The present study aimed to re-examine the clinicopathological features of these four 'unusual' cases, and the results indicated the histopathological variation in MLS.

\section{Materials and methods}

Case selection. The patients included in this study were 2 males and 2 females, ranging in age from 32 to 74 years (mean 59), who presented with a mass lesion ranging from 2.5 to $14 \mathrm{~cm}$ in size. After written informed consent was obtained, tissues from 74 liposarcomas obtained at the time of surgery, and stored at $-80^{\circ} \mathrm{C}$, were analyzed by reverse transcription-polymerase chain reaction (RT-PCR) and DNA sequencing 
Table I. Clinicopathological characteristics of four cases with detectable TLS-CHOP or EWS-CHOP transcripts whose diagnosis was other than myxoid liposarcoma.

\begin{tabular}{|c|c|c|c|c|c|c|c|c|c|}
\hline No. & $\begin{array}{l}\text { Age/ } \\
\text { Gender }\end{array}$ & Location & $\begin{array}{l}\text { Size } \\
(\mathrm{cm})\end{array}$ & $\begin{array}{c}\text { Postoperative } \\
\text { diagnosis }\end{array}$ & $\begin{array}{l}\text { Differential diagnosis } \\
\text { and dominant cells }\end{array}$ & $\begin{array}{l}\text { Myxomatous } \\
\text { component }\end{array}$ & $\begin{array}{l}\text { Adjuvant } \\
\text { therapy }\end{array}$ & $\begin{array}{l}\text { Follow-up after } \\
\text { wide resection }\end{array}$ & $\begin{array}{c}\text { Fusion } \\
\text { gene }\end{array}$ \\
\hline 1 & 70/M & Thigh & $>10$ & WDLS & ND & ND & No & 72 mo ANED & $T L S-C H O P$ \\
\hline 2 & $74 / \mathrm{F}$ & Thigh & 2.5 & DDLS & $\begin{array}{l}\text { Pleomorphic sarcoma, } \\
\text { spindle cells }\end{array}$ & $<10 \%$ & No & 129 mo ANED & $T L S-C H O P$ \\
\hline 3 & $58 / \mathrm{M}$ & $\begin{array}{c}\text { Retro- } \\
\text { peritoneum }\end{array}$ & ND & DDLS & $\begin{array}{l}\text { Pleomorphic MFH, } \\
\text { spindle cells }\end{array}$ & $<10 \%$ & $\begin{array}{l}\text { Chemo, } \\
\text { Radio }\end{array}$ & $\begin{array}{l}22 \mathrm{mo} \mathrm{rec} \\
40 \mathrm{mo} \mathrm{SD}\end{array}$ & EWS-CHOP \\
\hline 4 & $32 / \mathrm{F}$ & Back & 14 & Unclassified & $\begin{array}{l}\text { Synovial sarcoma, } \\
\text { spindle cells }\end{array}$ & $<5 \%$ & Chemo & $\begin{array}{c}36 \text { mo ANED } \\
\text { DID }\end{array}$ & TLS-CHOP \\
\hline
\end{tabular}

ANED, alive no evidence of disease; DDLS, de-differentiated liposarcoma; DID, deceased independent of disease; SD, succumbed to disease; F, female; M, male; MFH, malignant fibrous histiocytoma; mo, months; ND, no data; rec, local recurrence; WDLS, well-differentiated liposarcoma; Chemo, chemotherapy; Radio, radiotherapy.
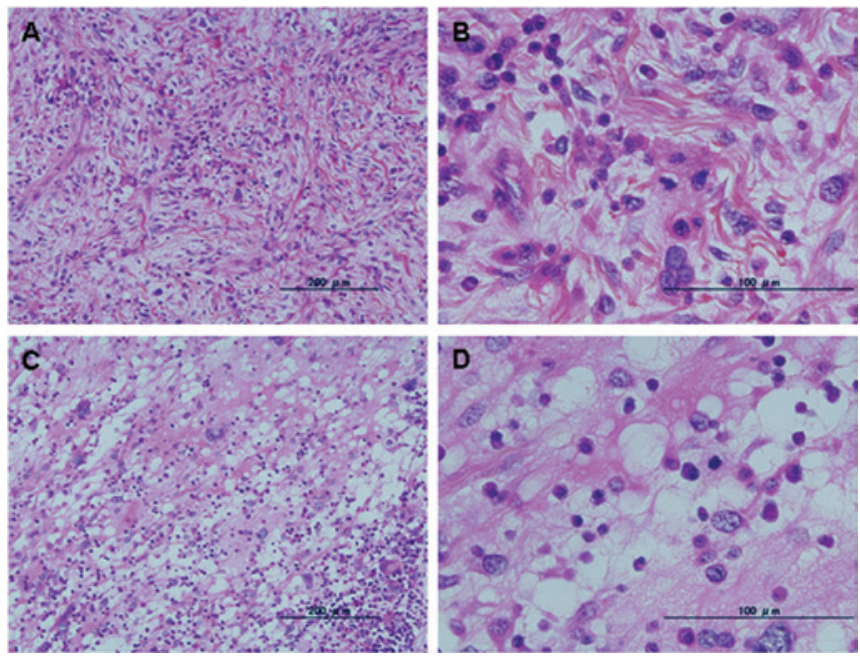

Figure 1. Histopathological re-examination of the biopsy specimen (case 2). (A) The dominant component $(>90 \%)$ showed variable cellularity and cytological pleomorphism with collagenous matrix, an appearance of pleomorphic sarcoma (magnification, x100). (B) High-power magnification of the dominant component contained large bizarre cells with foamy cytoplasm (magnification, $\mathrm{x} 400)$. (C) The minor component $(<10 \%)$ contained abundant intercellular myxoid stroma with notable infiltration of inflammatory cells (magnification, x100). (D) High-power magnification of the minor component (magnification, $\mathrm{x} 400)$. Hematoxylin and eosin staining.

for possible detection of the TLS-CHOP or EWS-CHOP transcripts (10). Histological subtypes of liposarcomas, determined by pathologists, consisted of 12 well-differentiated, 41 MLS, 4 de-differentiated, and 17 unclassified. Out of the 74 liposarcomas, $22(30 \%)$ were associated with the TLS-CHOP fusion transcript, whereas $3(4 \%)$ were associated with the $E W S-C H O P$ fusion transcript. Histological subtypes of TLS-CHOP detection consisted of 1 well-differentiated (8\% of the subtype), 19 MLS (46\% of the subtype), 1 de-differentiated ( $25 \%$ of the subtype) and 1 unclassified (6\% of the subtype). Histological subtypes of EWS-CHOP detection in liposarcoma included 2 MLS (2\% of the subtype) and 1 de-differentiated (25\% of the subtype). Based on the above, four cases of liposarcoma
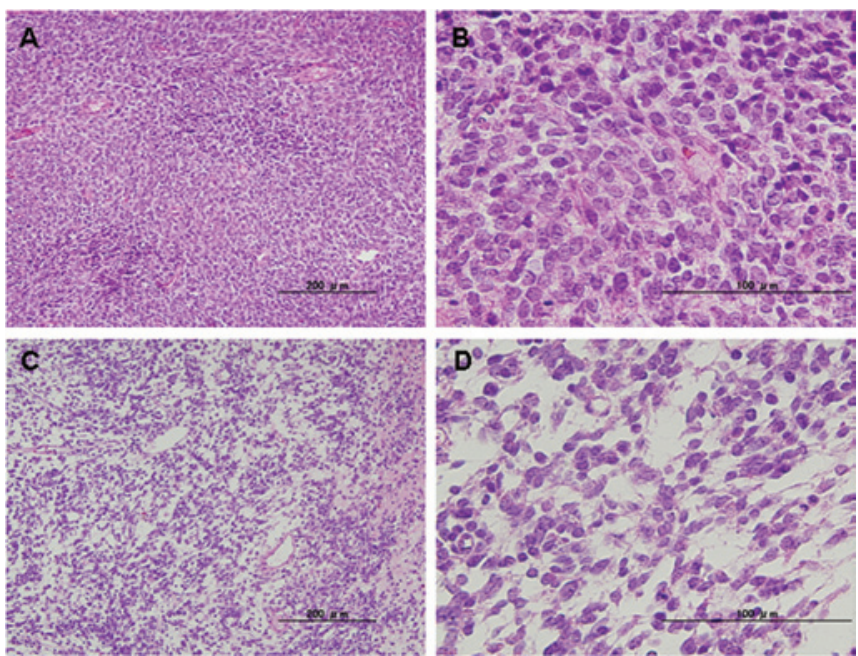

Figure 2. Histopathological re-examination of the biopsy specimen (case 4) (A) The dominant component $(>95 \%)$ consisted of fascicles and sheets of uniform, relatively small ovoid neoplastic cells, mimicking typical appearance of monophasic synovial sarcoma (magnification, x100). (B) High-power magnification of the dominant component (magnification, $x 400$ ). (C) The minor component $(<5 \%)$ contained small amount of intercellular myxoid stroma and neoplastic cells were not closely packed (magnification, x100). (D) High-power magnification of the minor component (magnification, $x 400$ ). Hematoxylin and eosin staining.

with detection of either TLS-CHOP or EWS-CHOP whose postoperative diagnosis was other than MLS were selected for the current study, consisting of re-examination of medical records, imaging data and histopathology. The procurement of frozen tissues and retrospective data collection were approved by the Review Boards of Osaka University Hospital and Osaka Medical Center for Cancer and Cardiovascular Diseases.

\section{Results}

Clinically, the patients were 2 male and 2 female, ranging in age from 32 to 74 (mean 59) years, and presenting with a mass lesion ranging from 2.5 to $14 \mathrm{~cm}$ in size (Table I). 

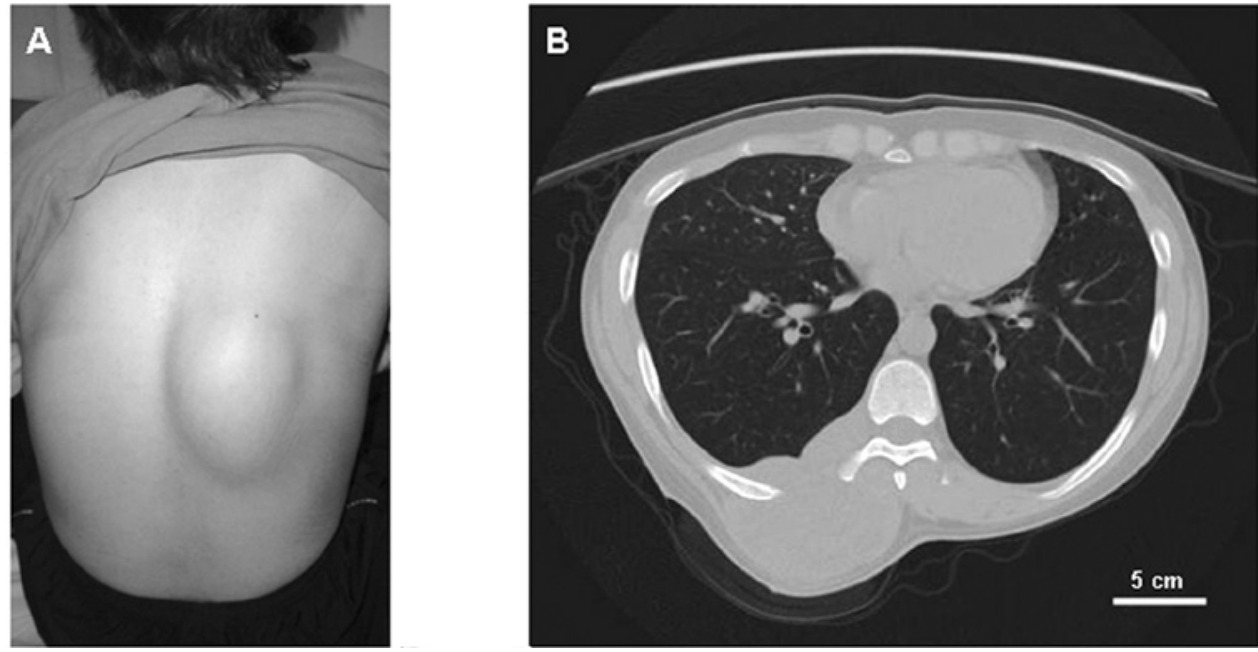

Figure 3. (A) Clinical image of case 4. A large mass located in the right section of the back. (B) Computed tomography image demonstrating the lesion mostly localized in the back muscle, partly penetrating into the thorax.

Postoperative diagnoses were well-differentiated liposarcoma (case 1), de-differentiated liposarcoma (cases 2 and 3), and unclassified (case 4). The patients underwent wide-resection with or without adjuvant therapy. Follow-up was available for all 4 patients and ranged from 36 to 129 months (mean 69) after surgery.

Re-examination of the clinical records identified that three of the four cases (cases 2, 3 and 4 in Table I) experienced considerable difficulty in making definitive diagnosis. Histopathologically, two cases postoperatively diagnosed as de-differentiated liposarcoma (cases 2 and 3 in Table I) exhibited variable cellularity and cytological pleomorphism, and contained large bizarre cells with foamy cytoplasm (Fig. 1A and 1B). In one case postoperatively diagnosed as unclassified (case 4 in Table I), spindle cells were densely proliferated (Fig. 2A and B); however, the tentative diagnosis of monophasic synovial sarcoma was postulated by the subsequent RT-PCR analysis, which did not detect any synovial sarcoma, translocated to $\mathrm{X}$ chromosome (SYT)-sarcoma, synovial, $\mathrm{X}$ breakpoint $(S S X)$ fusion transcripts for the definitive diagnosis (13). Re-examination of the histopathology identified that these three cases contained areas of myxomatous change as a minor component $(<10 \%)$ (Figs. 1C and D and $2 \mathrm{C}$ and $\mathrm{D})$.

Clinical report (case 4). A 32-year-old female presented with a large mass measuring $14 \mathrm{~cm}$ located on her back (Fig. 3A), which had occasional pain from one month prior to presentation. Computed tomography demonstrated that the mass lesion was predominantly located under the fascia of the back muscle, but partly penetrated into the thorax (Fig. 3B). Magnetic resonance imaging revealed non-homogeneous enhancement of the lesion following gadolinium diethylenetriaminepentaacetic acid injection. Open biopsy clearly supported the malignant nature of the lesion (Fig. 2A and B), and wide-resection was achieved with adjuvant pre- and post-operative chemotherapy. There were no signs of recurrence or metastasis prior to the patient's death due to suicide at 36 months after surgery.

\section{Discussion}

According to the World Health Organization (WHO) classification, MLS is defined as 'a malignant tumor composed of uniform round to oval-shaped primitive non-lipogenic mesenchymal cells and a variable number of lipoblasts in a prominent myxoid stroma with a characteristic branching vascular pattern' (2). In this retrospective analysis of four cases, their postoperative diagnoses, divided into various classes, were revised to MLS following the detection of the $T L S-C H O P$ or $E W S$-CHOP fusion transcripts. With the exception of one case (case 1) whose histopathological material was not available, re-examination proved that these cases shared a common characteristic, i.e., a myxomatous area as a minor component $(<10 \%)$, indicating that there are unusual MLS cases whose myxoid stroma is not prominent.

Dominant components $(>90 \%)$ of the current cases resembled pleomorphic sarcoma (case 2), pleomorphic malignant fibrous histiocytoma (case 3) and monophasic synovial sarcoma (case 4). In cases 2 and 3, the dominant component had been regarded as a de-differentiated feature of the de-differentiated liposarcoma. As shown in mixed-type liposarcomas consisting of combined patterns of well-differentiated liposarcoma and MLS, these cases (and possibly also case 1) may represent an extreme variant of the morphological spectrum within MLS (14). On the other hand, in case 4, the contradiction between histopathological appearance and the negative detection of SYT-SSX fusion transcripts resulted in a delay in classification, and this case was considered to comprise exclusively round-cell type MLS.

In conclusion, the present study indicates the histopathological variation in MLS and the significance of fusion gene detection for definitive diagnosis. In case of i) difficulty in providing definitive diagnosis of soft tissue sarcoma by standard histopathological examination; ii) negative detection of the histopathological candidate fusion gene (as in case 4 in this study); and iii) recognition of myxoid stroma even as a minor component, we propose that analysis of TLS-CHOP and EWS-CHOP fusion genes may aid diagnosis of unusual 
MLS. Further studies on the correlation between fusion genes and clinicopathological characteristics of MLS are required to establish the specific identity of this class.

\section{Acknowledgements}

This study was supported in part by the Japan Society for the Promotion of Science (Grant no. 22591683), the Nakatomi Foundation and the Osaka Medical Research Foundation for Incurable Diseases.

\section{References}

1. Weiss SW and Goldblum JR (eds): Liposarcoma. In: Enzinger and Weiss's Soft Tissue Tumors, 4th edition. Mosby, St. Louis, pp641-93, 2001.

2. Antonescu CR and Ladanyi M: Myxoid liposarcoma. In: World Health Organization Classification of Tumours: Pathology and Genetics of Tumours of Soft Tissue and Bone. Fletcher CDM, Unni KK and Mertens F (eds). IARC Press, Lyon, pp40-43, 2002.

3. Antonescu CR, Elahi A, Humphrey M, Lui MY, Healey JH, Brennan MF, Woodruff JM, Jhanwar SC and Ladanyi M: Specificity of TLS-CHOP rearrangement for classic myxoid/ round cell liposarcoma: absence in predominantly myxoid welldifferentiated liposarcomas. J Mol Diagn 2: 132-138, 2000.

4. Panagopoulos I, Mertens F, Isaksson M and Mandahl N: A novel FUS/CHOP chimera in myxoid liposarcoma. Biochem Biophys Res Commun 279: 838-845, 2000.

5. Antonescu CR, Tschernyavsky SJ, Decuseara R, Leung DH, Woodruff JM, Brennan MF, Bridge JA, Neff JR, Goldblum JR and Ladanyi M: Prognostic impact of P53 status, TLS-CHOP fusion transcript structure, and histological grade in myxoid liposarcoma: a molecular and clinicopathologic study of 82 cases. Clin Cancer Res 7: 3977-3987, 2001.
6. Hosaka T, Nakashima Y, Kusuzaki K, Murata H, Nakayama T, Nakamata T, Aoyama T, Okamoto T, Nishijo K, Araki N, et al: A novel type of $E W S-C H O P$ fusion gene in two cases of myxoid liposarcoma. J Mol Diagn 4: 164-171, 2002.

7. Domoto H, Hosaka T, Oikawa K, Ohbayashi T, Ishida T, Izumi $\mathrm{M}$, Iwaya $\mathrm{K}$, Toguchida $\mathrm{J}$, Kuroda $\mathrm{M}$ and Mukai $\mathrm{K}$ : TLS-CHOP target gene DOL54 expression in liposarcomas and malignant fibrous histiocytomas. Pathol Int 52: 497-500, 2002.

8. Bode-Lesniewska B, Frigerio S, Exner U, Abdou MT, Moch H and Zimmermann DR: Relevance of translocation type in myxoid liposarcoma and identification of a novel EWSR1-DDIT3 fusion. Genes Chromosomes Cancer 46: 961-971, 2007.

9. Alaggio R, Coffin CM, Weiss SW, Bridge JA, Issakov J, Oliveira AM and Folpe AL: Liposarcomas in young patients: a study of 82 cases occurring in patients younger than 22 years of age. Am J Surg Pathol 33: 645-658, 2009.

10. Kubo T, Matsui Y, Naka N, Araki N, Myoui A, Endo K, Yasui N, Ohtani O, Suzuki K, Kimura T, Yoshikawa H and Ueda T: Specificity of fusion genes in adipocytic tumors. Anticancer Res 30: 661-664, 2010.

11. Matsui Y, Ueda T, Kubo T, Hasegawa T, Tomita Y, Okamoto M, Myoui A, Kakunaga S, Yasui N and Yoshikawa H: A novel type of EWS-CHOP fusion gene in myxoid liposarcoma. Biochem Biophys Res Commun 348: 437-440, 2006.

12. Suzuki K, Matsui Y, Endo K, Kubo T, Hasegawa T, Kimura T, Ohtani $\mathrm{O}$ and Yasui $\mathrm{N}$ : Myxoid liposarcoma with EWS-CHOP type 1 fusion gene. Anticancer Res 30: 4679-4684, 2010.

13. Ladanyi M, Antonescu CR, Leung DH, Woodruff JM, Kawai A Healey JH, Brennan MF, Bridge JA, Neff JR, Barr FG, et al: Impact of SYT-SSX fusion type on the clinical behavior of synovial sarcoma: a multi-institutional retrospective study of 243 patients. Cancer Res 62: 135-140, 2002.

14. De Vreeze RSA, De Jong D, Koops W, Nederlof PM, Ariaens A, Haas RL and van Coevorden F: Oncogenesis and classification of mixed-type liposarcoma: a radiological, histopathological and molecular biological analysis. Int J Cancer 128: 778-786, 2011. 